\title{
SOJIZACIÓN Y ENFERMEDAD HOLANDESA eN Argentina: ¿LA MALdición VERde?
}

\author{
Alicia Puyana y Agostina Constantino*
}

Fecha de recepción: 19 de marzo de 2013. Fecha de aceptación: 05 de julio de 2013.

\section{RESUMEN}

La consolidación de Argentina como productor y exportador mundial de soja despegó a mediados de la década de 1990. Ahora bien, en los últimos años afloraron indicios que parecen sugerir que la economía Argentina padece los síntomas de "enfermedad holandesa", es decir, el retroceso prematuro de la agricultura y las manufacturas como fuente del Producto Interno Bruto y del empleo argentinos. Algunas de estas señas son la apreciación de tipo de cambio real (al mantener la tasa de cambio fija, cuando el país padecía elevada inflación) y el descenso en el superávit comercial. En este sentido, el objetivo de este trabajo es esclarecer si, en efecto, se detectan en la economía argentina los síntomas de la "enfermedad holandesa" como un fenómeno atribuible a la bonanza sojera que experimenta el país desde inicios de los ańos noventa.

Palabras clave: enfermedad holandesa, Argentina, soja, estructura productiva, desindustrialización.

\section{The Takeover of Soy and Dutch Disease In Argentina: An Agricultural Curse?}

\begin{abstract}
The consolidation of Argentina as a global producer and exporter of soy took off in the mid-1990s. However, in recent years, the evidence suggests that Argentina is suffering from the symptoms of "Dutch disease," which refers to the premature deterioration of agriculture and manufactures as a source of the gross domestic product and employment in the country. Some of these signs include appreciation of the real exchange rate (by maintaining a fixed exchange rate, the nation must deal with elevated inflation), and a falling commercial surplus. The objective of this work is therefore to clarify whether the economy of Argentina shows signs of "Dutch disease," a phenomenon attributable to the soy boom of the 1990s.
\end{abstract}

Key Words: dutch disease, Argentina, soy, productive structure, deindustrialization.

\footnotetext{
* Investigadoras de la Facultad Latinoamericana de Ciencias Sociales, sede México. Correos electrónicos: apuyana@flacso.edu.mx, agostina.costantino@flacso.edu.mx, respectivamente.
} 


\section{PASSAGE AU SOJA ET « MALADIE HOLLANDAISE » EN ARGENTINE : MALÉDIC- TION VERTE ?}

\section{Résumé}

La consolidation de l'Argentine comme producteur et exportateur mondial de soja a pris son envol à la moitié des années 90 . Or au cours des dernières années ont apparus des indices qui semblent suggérer que l'économie argentine montre les symptômes de la "maladie hollandaise», soit une régression prématurée de l'agriculture et des productions manufacturières comme source de produit intérieur brut et d'emploi pour l'Argentine. Certains de ces signes sont l'appréciation du taux de change réel (le régime de change fixe ayant été maintenu alors que le pays souffrait une inflation élevée) et la baisse de l'excédent commercial. Dans ce sens, le but de ce travail est d'éclaircir si on constate effectivement dans l'économie argentine les symptômes de la " maladie hollandaise » et si ce phénomène peut être attribué à la manne du soja dont le pays profite depuis le début des années 90 .

Mots clés : a maladie hollandaise, Argentine, soja, structure productive, désindustrialisation.

\section{SOJIZAÇÁO” E DOENÇA HOLANDESA NA ARGENTINA: A MALDIÇÁO VERDE? Resumo}

A consolidação da Argentina como produtora e exportadora mundial de soja decolou a mediados da década de 1990. Agora bem, nos últimos anos floresceram indícios que parecem sugerir que a economia Argentina padece dos sintomas da "doença holandesa", o que quer dizer do retrocesso prematuro da agricultura e as manufaturas como fonte do produto interno bruto e do emprego argentinos. Alguns desses sinais são a valorização do tipo de cambio real (ao manter a taxa de cambio fixa, quando padecia de elevada inflaçáo) e o descenso no superávit comercial. Neste sentido, o objetivo deste trabalho é esclarecer se, realmente, se detectam na economia argentina os sintomas da "doença holandesa" como um fenômeno que se pode atribuir à bonança da soja que experimenta o país desde o inicio dos anos noventa.

Palavras-chave: doença holandesa, Argentina, soja, estrutura produtiva, desindustrialização.

大豆和荷兰疾病接管在阿根廷：一个农业诅咒?

摘要:

阿根廷作为全球重要的大豆生产、出口国的地位是在20世纪90年代中期得 以巩固的。然而，近年来，有迹象表明阿根廷经历了“荷兰病”综合症， 这主要是指农业和工业部门在国内生产总值和就业中的过早恶化。其中一 些现象包括实际汇率升值（通过稳定规定汇率来实现，一国则必须应对高 通货膨胀）和贸易盈余下降。因此，本文的目标是澄清阿根廷经济是否出 现了由上世纪90年代“大豆繁荣”引致的“荷兰病”现象。

关键词：荷兰病 阿根廷大豆生产结构 去工业化 


\section{INTRODUCCIÓN}

La consolidación de Argentina como productor y exportador mundial de soja, un proceso denominado "sojización", despegó a mediados de la década de 1990, cuando este cultivo se expandió en la región pampeana. Esta trayectoria constituye una nueva fase del proceso de agriculturización de la economía y del sector primario argentino dada a luz durante la última dictadura militar (1976-1983), régimen que auspició el patrón de acumulación neoliberal, por medio de incentivos que fomentaron el abandono de las actividades ganaderas y su sustitución por actividades agrícolas. La soja fue el producto estrella de este modelo y lidera el crecimiento sectorial aún hoy.

Ahora bien, en los últimos ańos afloraron indicios que parecen sugerir que la economía argentina padece los síntomas de la famosa "enfermedad holandesa”, es decir, el retroceso prematuro de la agricultura y las manufacturas como fuente del Producto Interno Bruto y del empleo argentinos. Algunas de estas señas son la apreciación de tipo de cambio real (al mantener la tasa de cambio fija, cuando el país padecía elevada inflación) y el descenso en el superávit comercial. En atención a lo cual, el objetivo de este trabajo es esclarecer si, en efecto, se detectan en la economía argentina los síntomas de la "enfermedad holandesa" como un fenómeno atribuible a la bonanza sojera que experimenta el país desde inicios de los años noventa. Este modelo, como cualquier otro, posee limitaciones y deja variables fuera; no obstante, acotando la complejidad de la problemática abordada permite identificar el funcionamiento de ciertas variables y mecanismos. La bonanza, por el crecimiento de la demanda de China, está plenamente captada en la variable conformada con los precios de la soja, los cuales reflejan implícitamente los cambios tecnológicos cuyo efecto es que los precios no suban a tasas superiores al crecimiento de la demanda. Otra limitación se deriva de los problemas de la información estadística argentina, sometida recientemente a escrutinio. No obstante, se intenta con este ejercicio ilustrar claramente que, en efecto, Argentina presenta los síntomas de enfermedad holandesa, con sus pros y contras.

Para responder esta pregunta, luego de un breve repaso teórico en materia de enfermedad holandesa, se analiza la posibilidad de que haya enfermedad holandesa en el país mediante la elaboración de algunos indicadores específicos. 


\section{MARCO CONCEPTUAL ${ }^{1}$}

En el modelo básico de enfermedad holandesa, las bonanzas externas, inducidas por alzas de los precios de los productos de exportación (trigo, maíz, café, soja, etc.), o por el descubrimiento de yacimientos minerales, producen la contracción de los sectores productores comerciables o transables (de bienes exportables que no están en bonanza, o de importables, aquellos de producción nacional que compiten con las importaciones). Este encogimiento de las actividades vinculadas al comercio exterior es resultado de la apreciación de la tasa de cambio real, es decir, del crecimiento de la razón de los precios de los bienes no transables y los que sí lo son, y de la transferencia de los recursos productivos (mano de obra y capital) desde los últimos hacia los primeros. Estas tendencias se agravan por la característica inestabilidad de los precios de las materias primas: alzas intensas y contracciones severas que obligan a ajustes constantes en el gasto.

Los efectos de la bonanza de recursos naturales sobre la economía nacional se estudian en dos etapas. En la primera, se considera que su único efecto es el aumento en la demanda de mano de obra por el sector en bonanza, estimulado por su mayor rentabilidad. Toda vez que el modelo asume pleno empleo, este incremento de la demanda de mano de obra, eleva el nivel general de los salarios e induce una transferencia de trabajo, desde los sectores que no están en bonanza (el manufacturero y los servicios), hacia el sector en expansión. Este fenómeno conocido como el "efecto movimiento de recursos", deprime las manufacturas, el cual no se traduce en aumento de precios pues la demanda adicional se satisface con importaciones. De esta manera se mantiene el equilibrio del mercado pero con una menor producción interna. Se genera así, la llamada "desindustrialización directa". El desfase de la tasa de cambio real intensifica este efecto, agudizando el desempleo. La "desagriculturización", es el fenómeno, correspondiente al arriba mencionado, que se manifestó en los países petroleros, a consecuencia de las bonanzas de precios del petróleo en los años setenta.

En la segunda etapa, dos fenómenos revalúan la tasa de cambio real, es decir, el aumento en el precio relativo de los bienes del sector servicios (no transable). En primer lugar, a los precios relativos iniciales, el efecto movimiento de recursos reduce la oferta de servicios al propiciar la transferencia

Este apartado constituye un resumen del primer capítulo del libro de Alicia Puyana y Rosemary Thorp (1998). 
de mano de obra hacia el sector en bonanza y crea exceso de demanda por servicios y, por consiguiente, un incremento en su precio relativo. En segundo lugar, si parte de los ingresos adicionales provenientes de la bonanza se gasta internamente, y asumiendo que los servicios son bienes normales (es decir, la demanda por servicios aumenta cuando el ingreso crece), se incrementará su demanda, en una cantidad adicional al crecimiento impulsado por el efecto movimiento de recursos. Este fenómeno es conocido como el "efecto gasto". Éste y el "efecto movimiento de recursos" generan un exceso de demanda por servicios. Para restaurar el equilibrio en dicho mercado, el precio de los servicios aumenta, en términos relativos a las manufacturas.

Según el modelo de enfermedad holandesa, la estabilización de la economía resulta de los procesos explicados anteriormente, inducidos por los cambios en los precios relativos. Es decir, asume que la revaluación de la tasa real de cambio, efecto de una bonanza externa, es el mecanismo óptimo de ajuste del mercado ante un choque externo y, por lo tanto, no se justifica intervención alguna. Los supuestos básicos de este modelo son los principales de la teoría neoclásica, en la cual se parte de una situación de equilibrio para, después de un choque externo de carácter permanente, llegar a uno nuevo: $i$ ) ley de precio único; ii) pleno empleo y perfecta movilidad de los factores de un sector a otro, y iii) perfecta movilidad de salarios y precios.

Este modelo tiene severas limitaciones de especial relevancia para países como los latinoamericanos. Los supuestos de pleno empleo, precios flexibles y mercados competitivos no aplican a países en desarrollo, en los cuales el desempleo y el subempleo rural y urbano suelen ser la norma, amén de la extrema concentración del ingreso y todas las formas de capital: productivo, financiero, humano y de la tierra, de la cual la concentración en Argentina es muy elevada y al alza. Ello significa que ni el efecto de movimiento de recursos ni el del gasto, operan en el sentido o la inmediatez supuestos por la teoría.

Los enfoques keynesianos y estructuralistas cuestionan la validez del modelo neoclásico, especialmente tratándose de países en desarrollo. El primer enfoque considera que el nivel de producción está determinado por la demanda y el efecto gasto podría expandir la oferta nacional de bienes transables, si antes de la bonanza había recursos sin usarse. Por su parte, el enfoque estructuralista va más allá pues además de no aceptar la vigencia del precio único y el pleno empleo, duda del poder de los precios relativos para asignar oportunamente los recursos, enfatiza las diferencias sectoriales y considera que, a pesar de haber factores ociosos, la oferta sectorial resulta inelástica a los cambios en los precios relativos. En estas condiciones, una bonanza podría dar lugar a cambios sustanciales en los precios relativos con un limitado efecto 
sobre la estructura económica. Por otra parte, una revaluación real, tal como la considerada por el modelo convencional de enfermedad holandesa, podría tener efectos adversos sobre la distribución del ingreso al beneficiar a sectores rentistas y perjudicar a los más dinámicos.

En el largo plazo, la evolución de la economía de un país resulta determinada por el efecto de los choques externos, positivos y negativos, sobre el proceso ahorro-inversión y sobre los encadenamientos de la actividad primaria. En una función exportadora como la sojera en Argentina, donde la producción está altamente concentrada en unos pocos pero grandes productores y el Estado sólo tiene participación por medio de los impuestos que cobra (tanto a las exportaciones de este cultivo, a las ganancias de los productores, impuestos inmobiliarios, etc.), los encadenamientos serán más débiles (tanto por la concentración de la capacidad de consumo de los grandes terratenientes como por la poca mano de obra que demanda la actividad) y el efecto final dependerá de factores políticos e institucionales, de las políticas que se diseñen para absorber el flujo de recursos adicionales.

En este sentido, se justificaría proteger algunos sectores de bienes transables, si su valor social diverge del privado, debido a consideraciones de distribución del ingreso, con el fin de explotar las externalidades o por el de aprendizaje. Además, una importante serie de argumentos sobre la necesidad de cierto grado de intervención estatal se centra en los aspectos desestabilizadores de la inestabilidad de los precios de exportación la cual afecta la capacidad de inversión interna y por esta vía a la tasa de crecimiento económico, además de la diversificación de la estructura productiva, de la estructura del empleo y los ingresos fiscales.

\section{¿HAY ENFERMEDAD HOLANDESA EN ARGENTINA?}

Desde los inicios de la primera década del siglo XxI, el auge de la demanda de cultivos "comodín" (es decir, aquellos que sirven tanto como alimentos, forrajes e insumos para biocombustibles), estimuló el crecimiento de su producción, en particular de soja, acelerando en Argentina el crecimiento de este producto, cuyo cultivo creció fuertemente desde mediados de la década de los noventa.

Se intenta evaluar en esta sección la posibilidad de que haya enfermedad holandesa en Argentina, es decir, si la bonanza experimentada por el sector productor de soja, al inducir la apreciación de la tasa de cambio real, afecta la estructura productiva y auspicia el retroceso prematuro de los sectores transa- 
bles que no estén en bonanza. Ahora bien, este país es altamente eficiente en agroindustria y en insumos industriales de uso difundido (acero, aluminio, etc.), los cuales podrían beneficiarse de la bonanza sojera, si los insumos que este cultivo demanda se abastecen con producción nacional (siempre y cuando Argentina los produzca a precios cercanos a los internacionales). De ser así, la parte del movimiento de factores (mano de obra y capital) se dirigiría hacia estas actividades manufactureras. En este sentido la actividad sojera podría atraer recursos (tanto de capital como de mano de obra y tierra destinada a otros usos) sin que, necesariamente, esto vaya en detrimento de los recursos disponibles para otras actividades (siempre que haya abundancia de capitales).

Según Bisang (2011), hay una particularidad en el caso argentino que lo distingue del caso típico concebido en la teoría: las rentas del sector (en este caso, el sojero) no se generaron sólo a partir de una mejora en los precios para una cantidad dada de recursos naturales, sino que lo hicieron a partir de la incorporación de tecnología al sector (que aumentó la tierra cultivable al permitir la incorporación de nuevas tierras, elevó los rendimientos por hectárea y la rentabilidad del capital). En este sentido, según el autor, el punto clave en Argentina deberían ser las políticas públicas referidas al tipo de cambio real que no afecten los incentivos a la innovación, por ejemplo, según el propio autor, el desarrollo de nuevas variedades de semillas aptas para los suelos argentinos.

El precio de la soja ha experimentado una tendencia al alza desde 1999. Como puede verse en la gráfica 1, la tendencia polinómica mostró un pico en el año 1971 para luego descender tendencialmente hasta 1999 y a partir de allí comenzar a crecer de nuevo. Esto es lo que José Antonio Ocampo (2011) ha denominado los "súper-ciclos" de los precios de las materias primas no petroleras, es decir, ciclos de largo plazo que responden a cambios en la economía mundial, tanto a la dinámica del crecimiento como a los aspectos tecnológicos específicos de cada etapa. El autor ha identificado cuatro súper-ciclos (para el precio de todas las materias primas no petroleras) desde la etapa del modelo agroexportador, más precisamente desde 1884: 1884-1932; 1932-1971; 1971-1999; 1999-actual. ${ }^{2}$

2 Según Ocampo, el porcentaje de aumento de los precios durante cada auge es inferior al anterior, lo cual avalaría la tesis Prebisch-Singer respecto de la caída tendencial en los precios de las materias primas. De hecho, Erten y Ocampo (2012) calculan que el porcentaje de crecimiento en el precio de los productos agrícolas de clima templado en el último súper-ciclo fue de $59.7 \%$, mientras que en el súper-ciclo anterior este aumento fue de 66.1 por ciento. 
Gráfica 1. Precio de la soja en dólares constantes de 2005

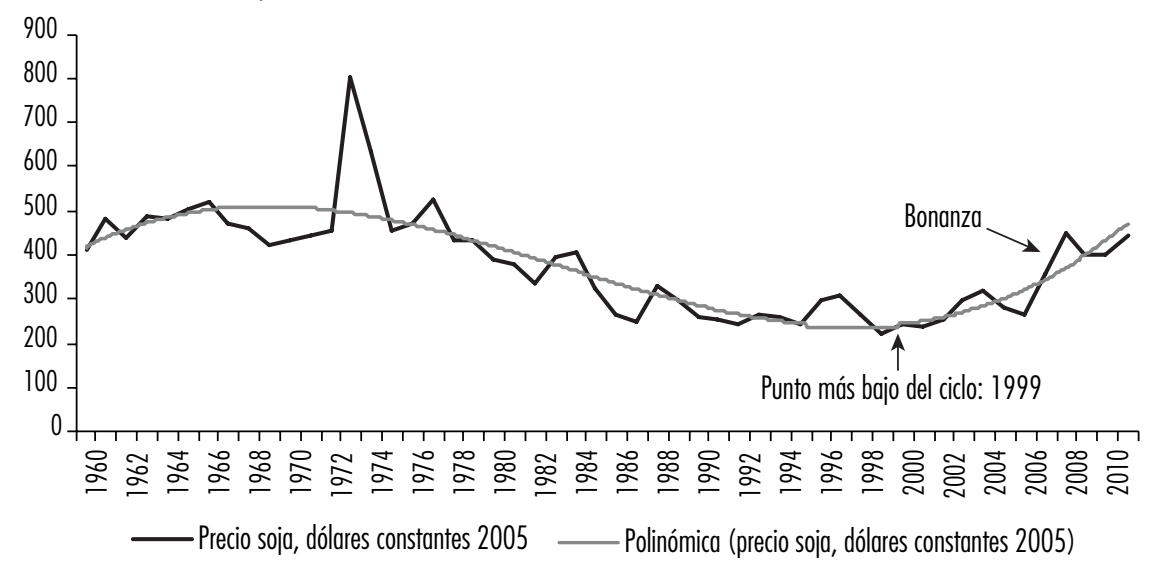

Fuente: Elaboración propia con base en el Banco Mundial.

Volviendo a la gráfica 1, se muestra que durante el actual súper-ciclo, el precio de la soja ha crecido $98.5 \%$. Se trata de una bonanza de precios internacionales de gran intensidad y larga duración (de 13 años). Como en otra oportunidad (Costantino, 2012), se puede proponer las siguientes razones de esta bonanza, además de factores que van más allá de las consideraciones sobre el equilibrio entre la oferta y la demanda, sin pretender sugerir ningún ordenamiento de prioridad: $i$ ) el aumento del precio de petróleo (que influye en los alimentos por vía del incremento en los costos de producción y por el aumento en la demanda de los mismos para la producción de biocombustibles); ii) la depreciación del dólar desde los setenta (que afecta al precio de los alimentos por vía del aumento en la demanda de los compradores de materias primas cuyos ingresos no son en dólares), y iii) la especulación financiera, es decir, las inversiones financieras y especulativas en el mercado de la soja serían un factor más que influye sobre su precio (Cooke y Robles, 2009).

Un comentario adicional respecto de esta bonanza, y siguiendo con el planteo de Ocampo de las tasas de crecimiento de los precios cada vez más pequeñas con respecto a los ciclos anteriores, es que el actual crecimiento de precios no ha logrado generar un excedente neto en valores respecto de la fase previa de declive de precios. En la gráfica 2, se muestra este excedente calculado de la siguiente manera:

Excedente neto $=\left(P_{\text {año corriente }}-P_{\text {promedio 1971-1998 }} *\right.$ Cantidad exportada de soja

Donde $P$ es el precio de la soja en dólares constantes de 2005. 
Gráfica 2. Excedente del valor de las exportaciones de soja respecto de la fase de precios anterior (1971-1998)

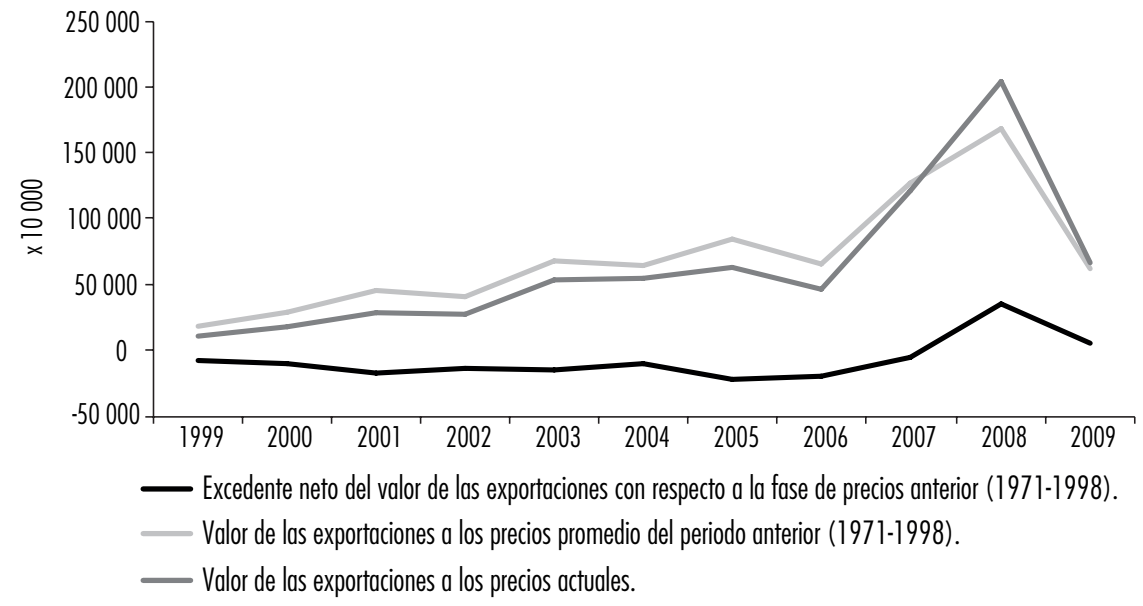

Fuente: Banco Mundial.

Tal como afirma Ocampo (2011), las bonanzas en los precios agrícolas tienden a ser cada vez más pequeños, lo cual explica que aunque el alza de precios se haya iniciado 10 ańos antes el valor de las exportaciones de soja no recupera los valores promedio de la fase anterior antes de 2008. Esto explica también que, para mantener la tasa de crecimiento del ingreso, los argentinos deban exportar cada vez mayores volúmenes del grano.

Tal como lo predice la teoría de la enfermedad holandesa, hay indicios (gráfica 3) que desde la devaluación en diciembre del 2002, la tasa de cambio del peso argentino (medida como cantidad de pesos para adquirir un dólar) se ha apreciado, lo cual sugeriría que la entrada de dólares por las exportaciones de soja y por inversiones en este sector al revaluar la moneda, mina la competitividad de otros sectores de la economía. Este punto es controvertido. Mientras Eduardo Levy Yeyati, sugiere que la apreciación del peso podría responder al aumento de los precios y la productividad relativa del sector granario, Martín Rapetti y José María Fanelli afirman que la apreciación cambiaria se explica por la política macroeconómica local (Burgo, 2012). ${ }^{3}$

3 El Instituto Nacional de Estadísticas y Censos (INDEC) de Argentina se encuentra intervenido desde el año 2006. A partir del 2007 el gobierno comienza a modificar la metodología de medición de los precios del índice de precios al consumidor, lo cual ha resultado una medida muy controvertida debido a las críticas que esta medición ha recibido de los especialistas. La principal es que el índice medido por el gobierno no refleja el verdadero costo de la canasta y que, por lo tanto, la inflación sería aún mayor a la que publica el gobierno. Esto no afecta nuestro trabajo pues si la inflación oficial está subestimada, entonces la apreciación cambiaria sería aún mayor que la que aquí se muestra. 
Gráfica 3. Tipo de cambio real desde 2002 hasta 2011, pesos por dólar

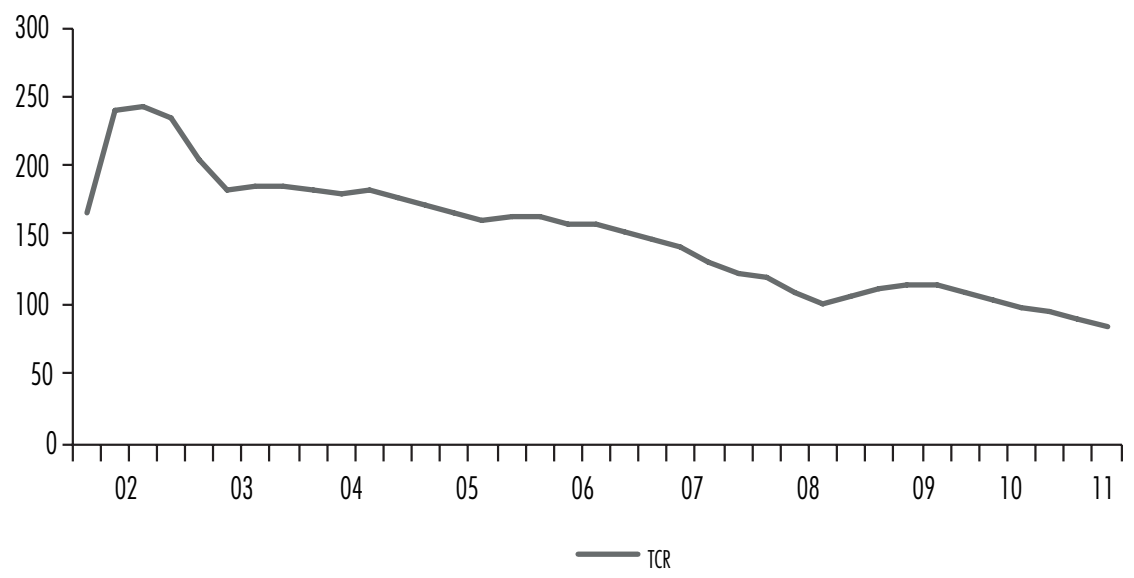

Fuente: Banco Central de la República Argentina y CENDA.

Más allá de la discusión anterior, parecería haber, sin embargo, una relación entre esta apreciación cambiaria y el crecimiento de las exportaciones de soja. La gráfica 4 muestra una aceleración en el crecimiento de las mismas a partir de 1999, momento en el que el precio de la soja comienza a aumentar: la tasa de crecimiento media anual pasa de 9.7\% antes de 1999 , a $15.5 \%$ a partir de ese año.

Tal como se anticipa en la teoría, tanto el ingreso de divisas por la mayor exportación de soja como el aumento en el precio relativo de los bienes no transables harán que se acelere el crecimiento de este último y que se desacelere el crecimiento en el sector del resto de los bienes transables tradicionales (como las manufacturas de origen industrial y otros productos agrícolas que no están en bonanza) tanto por el efecto de movimiento de recursos (reorientación del capital, el trabajo y en este caso de la tierra, desde el resto de los sectores hacia el sector en pujanza) como por el efecto gasto, público y privado (por la apreciación del tipo de cambio real).

Como se muestra en la gráfica 5, los sectores de servicios y construcción (ambos no transables) han experimentado una aceleración en su crecimiento a partir del momento en que comenzó a aumentar el precio de la soja: el sector servicios pasó de crecer en promedio 3.5\% antes de la escalada del precio de la soja (en el periodo 1991-1999), a una media de 4.3\% anual a partir de ese año (1999-2011); y es aún más fuerte lo ocurrido con el sector de la construcción, que pasó de crecer 3.2\% a casi duplicar esta tasa de crecimiento anual luego de que en 1999 lo hizo a 6\% en promedio. 
Gráfica 4. Tasa de crecimiento anual promedio de las exportaciones de soja de Argentina

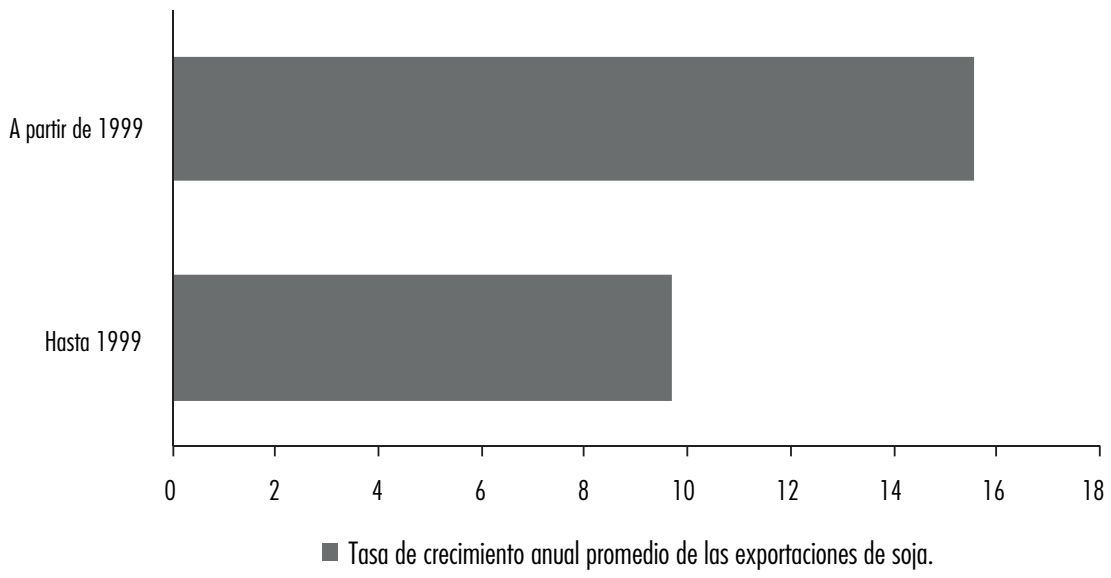

Fuente: Fuostat.

Gráfica 5. Tasa de crecimiento anual promedio de los sectores no transables: servicios y construcción

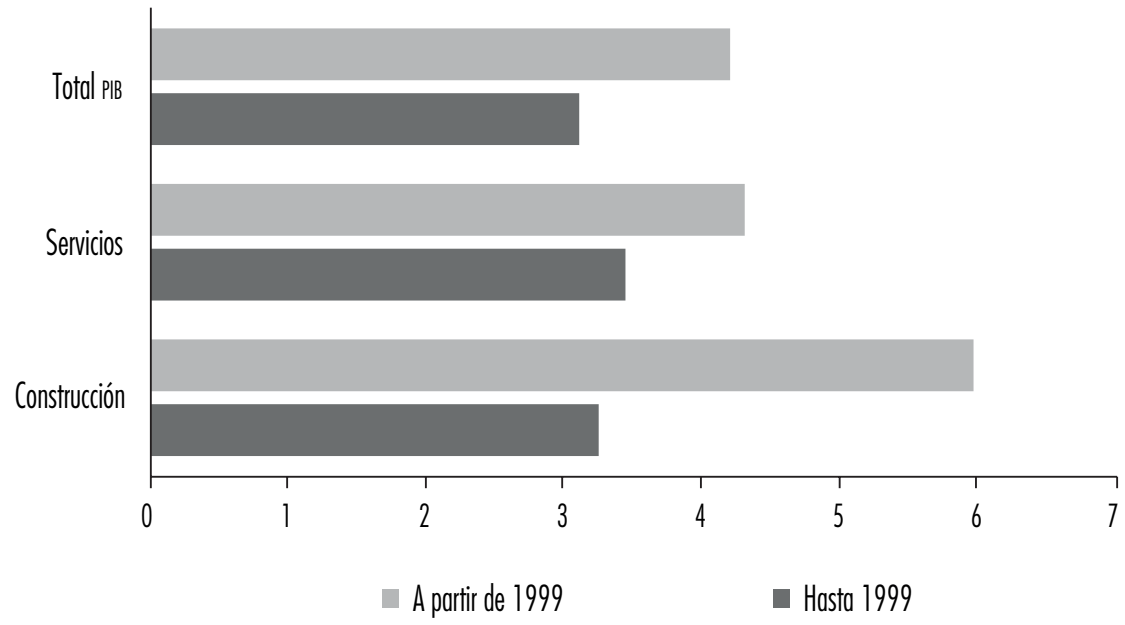

Fuente: Elaboración propia con base en los datos del INDEC. Los datos del 2000 al 2011 son estimaciones preliminares.

El comportamiento del sector de los bienes transables es el que presenta el resultado más interesante. El cuadro 1 muestra las tasas de crecimiento anual promedio de los sectores transables y de crecimiento del PIB per cápita en tres periodos distintos. Como puede verse, en 1982-1991 tanto las tasas de crecimiento de las manufacturas como la del PIB tenían signo negativo, reflejando 
la crisis del modelo de industrialización guiado por el Estado, vigente durante las décadas previas, en la siguiente (1991-1999) se observa una recuperación en el crecimiento de estos dos sectores. Sin embargo, en el periodo 19992011, también coincidiendo con las predicciones de la teoría, se observa una desaceleración del sector agricultura (por el retroceso de actividades que no estaban en bonanza como el sorgo y el girasol). En este caso, la tasa de crecimiento es menor con respecto a la del pIB per cápita a partir de 1999 (mientras que antes de 1999, ambas tasas eran mayores a la del PIB). Ahora bien, como puede verse en el cuadro 1, a partir de 1999 se dio una aceleración en la tasa de crecimiento del sector manufacturero (que también superó a la del pIB total), el cual pasó de crecer 3.7\% anual en el periodo 1991-1999, a 4.2\% anual en promedio a partir de dicho año. Es decir, la bonanza no parece intensificar el retroceso de las manufacturas si no detenerla.

Cuadro 1. Tasas de crecimiento anual promedio de los distintos sectores

\begin{tabular}{lccc}
\hline & $1982-1991$ & $1991-1999$ & $1999-2011$ \\
\hline Agricultura, valor agregado (\% de crecimiento) & 1.2 & 3.8 & 3.5 \\
Manufactura, valor agregado (\% de crecimiento) & -0.7 & 3.7 & 4.2 \\
Crecimiento PIB per capita (\% annual) & -2.4 & 4 & 3.5 \\
\hline
\end{tabular}

Fuente: Elaboración propia con base en el Banco Mundial (World Development Indicators)

Ahora bien, con esto se pretende afirmar que hay en Argentina un proceso interesante, que se ilustra en la gráfica 6 . El sector manufacturero ha retrocedido como fuente del PIв hasta representar 17.8\% en 2011. El declive prácticamente ininterrumpido de este sector se inició a finales de los años sesenta y muestra un leve repunte entre 2000 y 2004. La trayectoria de la agricultura ilustra la discriminación durante la sustitución de importaciones y la casi nula reactivación con el modelo neoliberal. En 2011, este sector representó 9\% del PIв. Los años de recuperación de los dos sectores, 2002-2004, sugieren los efectos de la devaluación del peso argentino.

Podría sugerirse que ha sido más intenso el retroceso del sector manufacturero, cuya participación en el PIB, entre 1965 y 2011 se mermó en 24 puntos porcentuales, mientras que la agricultura lo hizo en medio punto. Si este cambio estructural se considera a partir de 1996 y hasta 2011, las manufacturas retrocedieron cuatro puntos del PIB mientras la agricultura avanzó 3.1 puntos 
Gráfica 6. Participación de los distintos sectores en el PIB (\%)

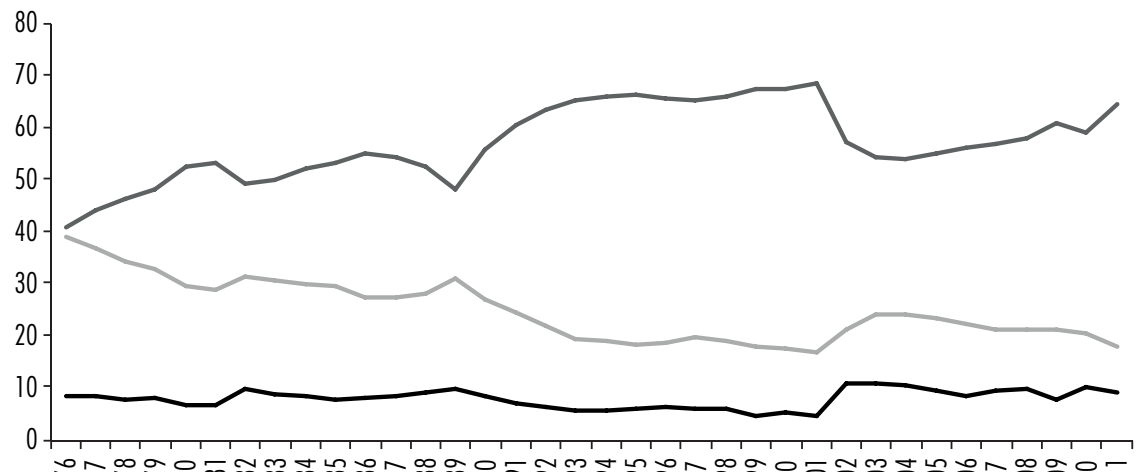

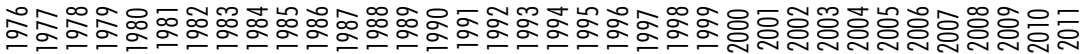

— Agricultura, valor añadido (\% de GDP) - Fabricación, valor añadido (\% de GDP) — Servicios, etc., valor añadido (\% de GDP)

Fuente: Banco Mundial.

porcentuales, trayectorias divergentes que parecerían confirmar la re-agriculturización de la economía nacional. La productividad del sector y la fuerza de los grandes productores y exportadores de granos, especialmente de la soja, parecería que han logrado, no sólo frenar si no revertir la caída de la agricultura y elevar su contribución al PIB, más allá de lo que dictaría la conocida norma Chenery, ${ }^{4}$ como se muestra enseguida. La norma establece que para el PIB per cápita de Argentina de 2012, la participación de las manufacturas debería ser cercana a 28\% del PIB y la de la agricultura de 7\%. En la primera actividad, Argentina tiene un rezago de 10.2 puntos porcentuales mientras que la agricultura supera la norma con dos puntos. Es decir, al nivel de desarrollo de Argentina, medido por el PIB per cápita, la agricultura tiene un peso mayor al de la norma mientras las manufacturas acusan un severo índice de enfermedad holandesa, o un retroceso prematuro. No obstante, es necesario recalcar que el menor crecimiento de las manufacturas argentinas es marginal

4 La metodología creada por Chenery y Syrquin establece cuál debe ser la estructura considerable como la normal participación sectorial en el PIB y el empleo, de acuerdo al nivel de desarrollo de cada país, medido por el PIB por habitante. La diferencia entre la participación de los sectores transables y la observada muestra el índice de la enfermedad holandesa, es decir, mide el retroceso prematuro de los sectores transables. Véanse: Chenery, Syrquin y Robinson (1986). 
y no acusa la severidad de otros países, por ejemplo de Brasil, como se ilustra en el cuadro 2. La crisis de enfermedad holandesa la experimentó el país entre 1980 y 2000, para el año 2011, el índice de enfermedad holandesa creció 67\% por un ligero avance de la participación de las manufacturas en el PIB y uno, considerablemente mayor, de la agricultura.

El relativo, si bien menor repunte de las manufacturas, parecería no avalar plenamente lo propuesto por la teoría de la enfermedad holandesa, por lo cual se considera necesario responder por qué el sector manufacturero crece a tasas no muy alejadas del PIB total o de la agricultura no obstante ser éste el sector en bonanza y disfrutar la formidable expansión de la demanda de soja del mundo y de los diversos estímulos políticos instituidos por los sucesivos gobiernos. Hay varios indicios que podrían explicar cuáles han sido los factores que suavizan los efectos de las desindustrializaciones anunciados por la teoría.

Se desea, en primer lugar, llamar la atención sobre la severidad de la desindustrialización y la desagriculturización de la economía brasileña, país que al igual que Argentina, experimenta la bonanza de los precios de soja y de otros productos agrícolas como la cańa de azúcar para el etanol. Brasil es el socio comercial latinoamericano más importante de Argentina y el principal mercado de destino de sus exportaciones manufactureras. No obstante tener un PIB per cápita menor, que representa sólo $40 \%$ del argentino, los sectores transables brasileños concentraron en 2011 una proporción mucho menor del PIB, por lo cual la brecha entre la participación normal y la observada es superior, confirmando una más severa desarticulación de la estructura productiva. Se sugiere que el incremento de la demanda de manufacturas en Brasil resultantes, de los efectos en el movimiento de factores y gasto de su bonanza, se satisface con importaciones principalmente de Argentina, dada la integración de las dos economías y las preferencias arancelarias del Mercosur.

En segundo término, como se muestra en la gráfica 7, el saldo comercial acumulado de todo el periodo 1999-2011 fue utilizado para financiar la salida de capitales del país evitando, de esta forma, que se apreciara aún más el peso y suavizando los efectos de la enfermedad holandesa, pero impidiendo la capitalización allí mismo. ${ }^{5}$ La forma en la que salieron estos capitales fue por medio

5 El acumulado de todas las cuentas se realizó excluyendo el año 1999 debido a que se ingresó el último pago correspondiente a la privatización de YPF, el último gran activo sometido a este tipo de venta. Por otra parte, se realizó el mismo ejercicio para el periodo 2002-2011 para corroborar que el fenómeno observado no se trataba de una característica del régimen del tipo de cambio. En este ejercicio, si bien con mayor intensidad, se observa el mismo comportamiento en las cuentas en 1999-2011. 
Gráfica 7. Destino del saldo comercial, acumulado 1999-2011

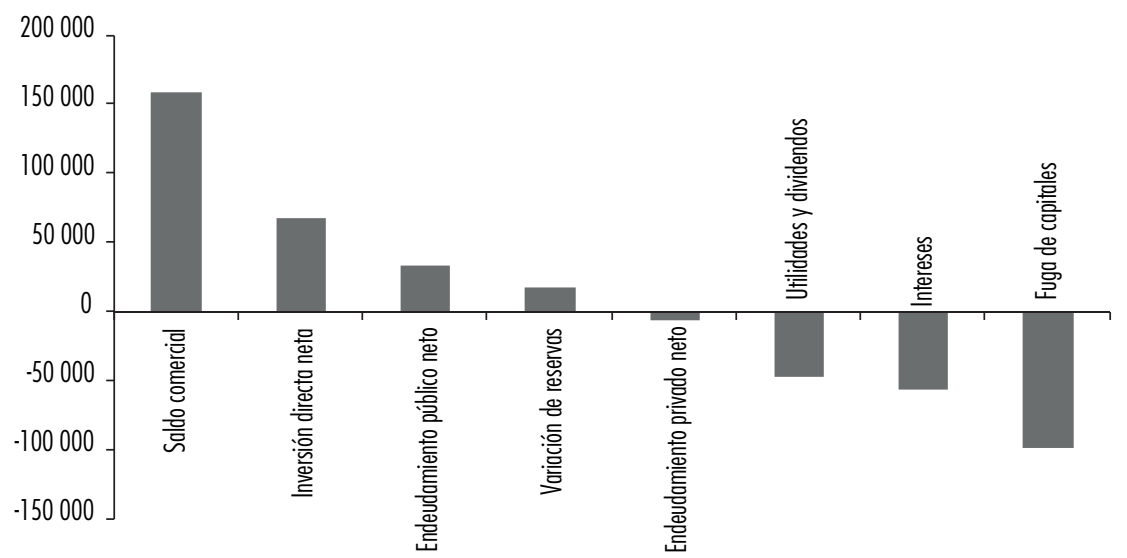

Fuente: Elaboración propia con base en datos del INDEC.

del pago de intereses, remisión de utilidades y fuga de capitales (depósitos en el extranjero, adquisición de activos no productivos en el exterior, etc.). De hecho, como puede verse, este saldo comercial por sí solo no fue suficiente para financiar el flujo de salida de capitales de la esfera de circulación nacional, sino que además se requirió del financiamiento por parte de la entrada neta de inversiones extranjeras y del endeudamiento en el exterior por parte del Estado. Todo esto evitó una mayor apreciación del tipo de cambio real permitiéndole a la industria que siguiera expandiendo su nivel de actividad.

¿A qué puede deberse esta fuga de capitales? Se puede pensar que, en situaciones de bonanza de un producto básico y en condiciones de apertura de la cuenta de capitales, si el sector no transables es intensivo en mano de obra, éste no absorbe el capital que se desplaza de los transables que no están en bonanza sino que sale del circuito de producción nacional.

Y, por último, un factor relacionado con la economía brasileña, y que puede explicar por qué el aumento del precio de la soja no ha infligido una contracción más severa del sector manufacturero, es la apreciación de la tasa de cambio del real brasileño. Como puede verse en la gráfica 8 , el tipo de cambio del real de Argentina con respecto a ese país ha tenido una tendencia creciente desde el 2002. Esta revaluación del real versus el peso, ha alterado los precios relativos de las manufacturas en favor de las argentinas, evitando que se perdiera competitividad en el mercado brasileño y frenado o reducido la contracción de su producción y de su participación en el PIB, de acuerdo a lo esperado por la teoría y en consonancia con la intensidad de la bonanza. 


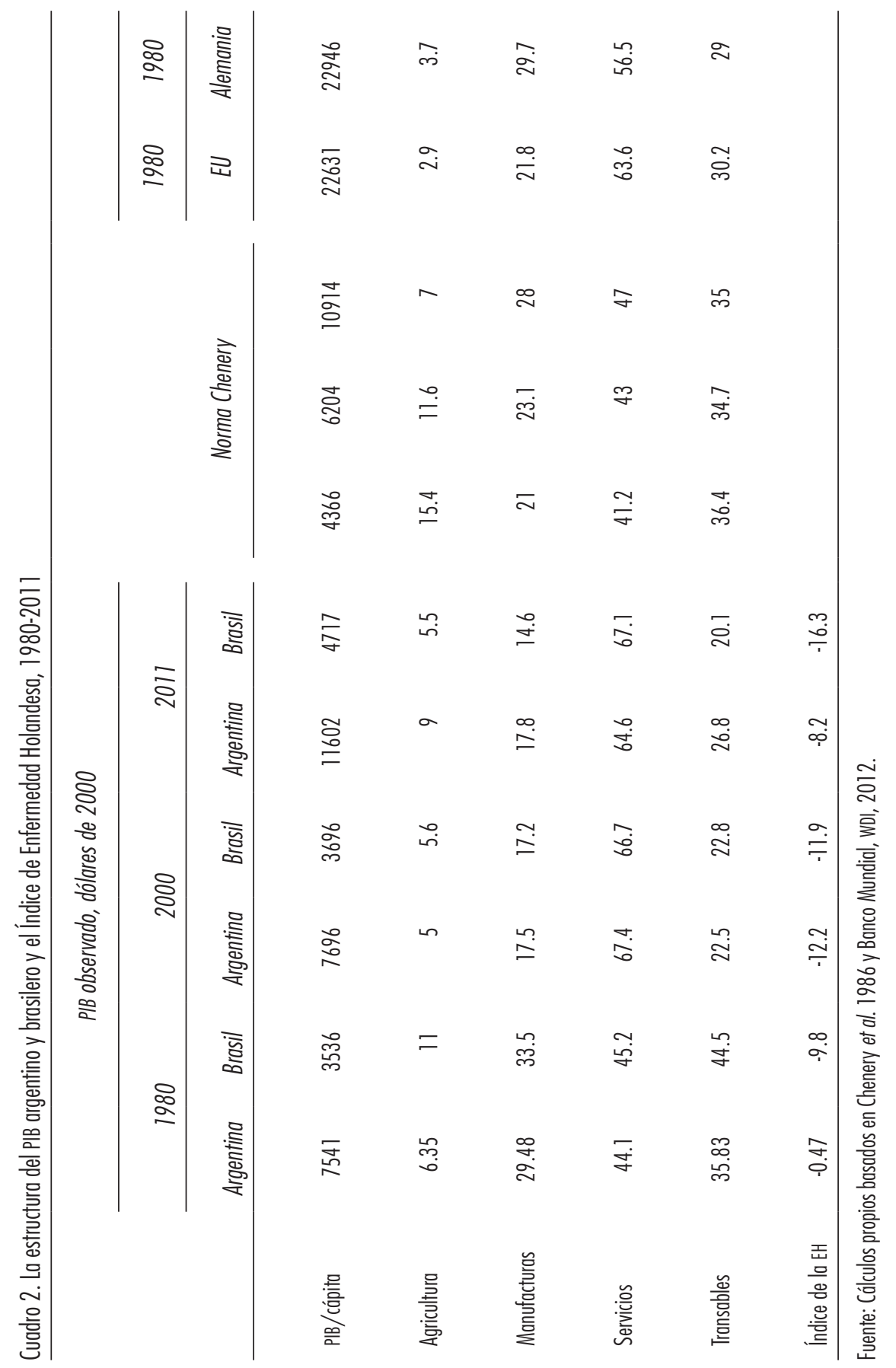


Gráfica 8. Tipo de cambio real entre Argentina y Brasil (cantidad de pesos argentinos para adquirir un real)

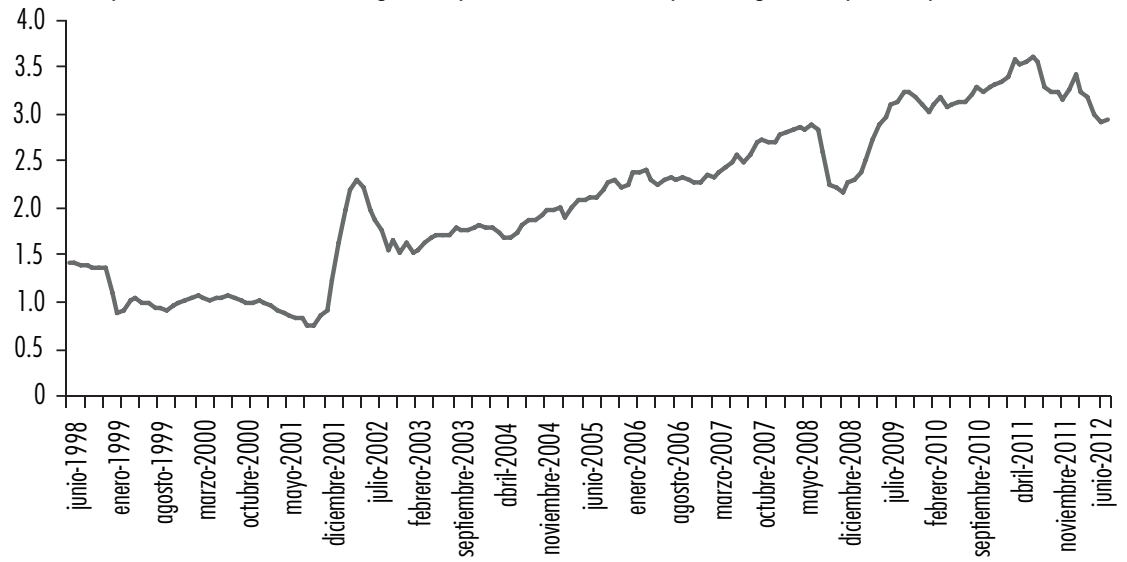

Fuente: Banco Central do Brasil.

Estas circunstancias pueden explicar el crecimiento de las manufacturas o la desaceleración del retroceso, ya que buena parte de las ventas argentinas a Brasil son manufacturas. Su oferta y las importaciones son elásticas a la tasa de cambio y a los precios, más que a las rebajas arancelarias. De todas formas, si bien la economía argentina se ha abierto, lo ha hecho menos que otras y si se eliminan el aumento del valor de las ventas de soya el grado de apertura sería menor.

Como se muestra en la gráfica 9 hay una correlación bastante elevada (siguen casi el mismo comportamiento) entre la producción industrial argentina y las exportaciones industriales a Brasil. Es decir, si bien buena parte de la "recuperación" del sector manufacturero se dio gracias a la "protección" otorgada por la devaluación del peso en 2002, una parte importante de esta producción ha podido recuperarse también por la relación de precios que hay con Brasil. ¿A qué responde esta apreciación del real con respecto al peso argentino? Hay muchas investigaciones que confirman una fuerte presencia de enfermedad holandesa en el país vecino y se especifica en el cuadro 2. Se piensa que, al ser más elevada la apreciación del real que la del peso (con respecto al dólar), Brasil responde a los efectos de su propia bonanza expandiendo sus importaciones de manufacturas desde Argentina y de esta manera absorbe y mitiga la enfermedad holandesa de ese pais. Es decir, Argentina se favorece de la severidad de la enfermedad holandesa de Brasil pues su desindustrialización (o la sustitución de importaciones provenientes de otros países) se refleja en un aumento de las importaciones industriales. 
Gráfica 9. Producción industrial argentina y exportaciones industriales a Brasil (millones de dólares de EU)

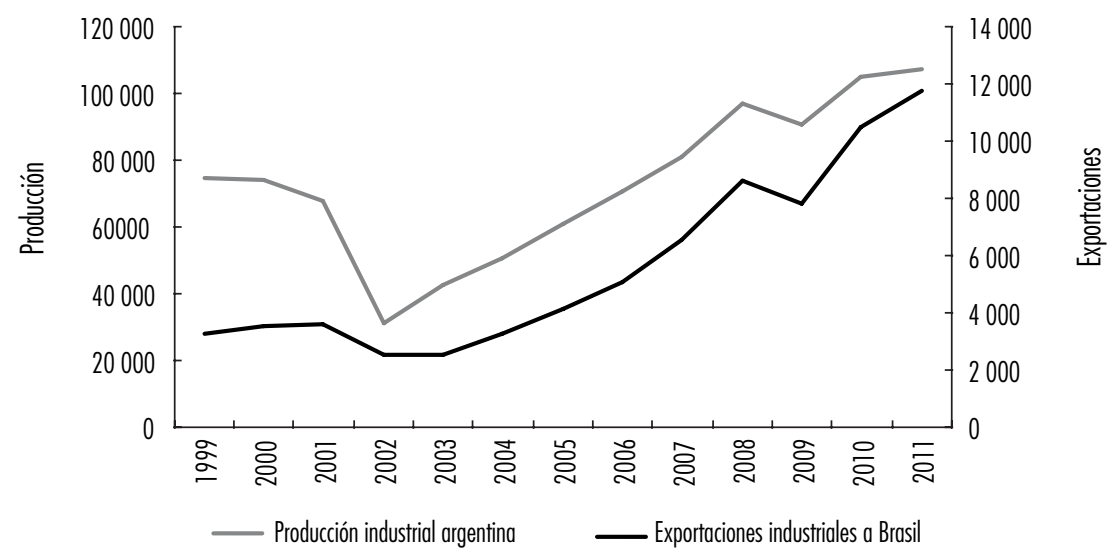

Fuente: Elaboración propia con base en BM e INTAL.

En definitiva, si bien pueden encontrarse en Argentina algunos signos de enfermedad holandesa, se muestra que algunas de sus consecuencias más temidas (como la desindustrialización) lograron amainarse gracias a la salida de capitales por fuera del circuito productivo nacional y a la apreciación del real brasileño, efecto de la bonanza productos agrícolas. Un equilibrio o dos vías altamente insostenibles, claro está.

\section{COMENTARIOS FINALES}

Una de las conclusiones más importantes de este trabajo es que la salida de capitales del país ha impedido la acumulación interna. Sin embargo, debido a que ésta impide la acumulación y a un contexto favorable en términos de la tasa de cambio con uno de los principales países compradores de los productores industriales argentinos (Brasil) el sector industrial no ha sufrido la contracción esperada y pudo sostener su participación en el PIB a lo largo de estos años (a pesar de que no se ha revertido el índice de enfermedad holandesa ni en la industria ni en la agricultura). Claramente, la industrialización por estas dos vías resulta insostenible a largo plazo, por lo que se requiere de una política industrial activa y de una protección de este sector.

Como afirma Rodrik (2009), el crecimiento de las naciones en desarrollo requiere que la economía mundial pueda absorber el rápido crecimiento en la oferta de los bienes producidos por ellos. En este sentido, los países de ingresos 
medios, productores de materias primas deben considerar, según el autor, el uso de medidas de promoción industrial explícitas (incluso subsidios) para bienes transables no tradicionales. Este tipo de subsidios puede aumentar su oferta, y que esto sea neutral con respecto a la balanza comercial. En efecto, la política industrial se puede asignar a la meta de la transformación estructural, mientras que la tasa de cambio a la balanza externa. Según Rodrik, la eliminación de la tasa de cambio real como un instrumento para el desarrollo no representa un costo para los países en desarrollo más grandes. Pero no darse cuenta de que hay métodos alternativos que se pueden utilizar como sustitutos puede, en gran medida, aumentar los efectos adversos sobre el crecimiento.

El objetivo de este trabajo es explicar la trayectoria del sector manufacturero argentino, evaluando si cabría la posibilidad de encontrar síntomas de enfermedad holandesa en esta situación. No se propuso, por ende, recomendar la aplicación de políticas para que el país saliera de su situación de pobre desempeño industrial, a partir de nuestra explicación. Se deja esto a los consultores y analistas especialistas en políticas públicas. No obstante, se sugiere algunas que se desprenden del estudio y vinculadas con los canales de transmisión de la enfermedad holandesa. Evitar la revaluación del real de la tasa de cambio y defender otros sectores transables; expandir el gasto público de forma que eleve la productividad de los sectores transables que no están en bonanza y establecer estímulos a sus exportaciones, finalmente, convertir el ingreso extraordinario del sector público en permanente, como vía para, por una parte, contener la revaluación y, por la otra, reducir los riesgos de la inestabilidad de los precios y de los ingresos fiscales.

\section{BIBLIOGRAFÍA}

Bisang, Roberto (2011), "Agro y recursos naturales en la Argentina: ¿enfermedad maldita o desafío a la inteligencia colectiva?", Boletín Informativo de Techint (336), pp. 63-83.

Burgo, Ezequiel (2012), “¿La Argentina, nueva víctima de la 'enfermedad holandesa?", Clarín, en: <http://www.ieco.clarin.com/economia/Argentina-nueva-victima-enfermedad-holandesa_0_623937838.html>

Chenery, Hollis Burnley; Moshe Syrquin, y Sherman Robinson (1986), Industrialization and growth: a comparative study, Nueva York, Banco Mundial.

Cooke, Bryce, y Miguel Robles (2009), "Recent food prices movements a time series analysis", IFPRI, Discussion Paper 00942, International Food Policy Research Institute. 
Alicia Puyana y Agostina Constantino

Costantino, Agostina (2012), La pampa sigue ancha y ajena: la persistencia del poder terrateniente en la región pampeana argentina durante la etapa de sojización, FLACSO México.

Erten, Bilge, y José Antonio Ocampo (2012), Super-cycles of commodity prices since the mid-nineteenth century en Economic \& Social Affairs, DESA, Working paper, núm. 110, Naciones Unidas.

Ocampo, José Antonio (2011), "El auge de los precios de productos básicos y el riesgo de enfermedad holandesa en América Latina", Boletín Informativo de Techint (336), pp. 25-48.

Puyana, Alicia, y Rosemary Thorp (1998), Colombia: economía politica de las expectativas petroleras, TM Editores, FLACSO/México, IEPRI.

Rodrik, Dani (2009), Growth after crisis, en Working papers, Harvard Kennedy School, Cambridge, MA 02138. 